\title{
A Term in Search of the Infrastructure of Electronic Markets
}

\author{
Jingzhi Guo \\ Department of Computer and Information Science, University of Macau \\ Av. Padre Tomás Pereira, S. J. Taipa, Macau, P.R.China jzguo@umac.mo
}

\begin{abstract}
The title of this paper was chosen to introduce what EM2I really means and how it could be treated as a research area for the research specialists of business information systems and electronic commerce. It functions as offering a few commonplace remarks by way of introduction so that the area researchers may come up with valuable opinions.
\end{abstract}

Keywords: Electronic marketplace, Business integration, Inter-enterprise integration, Internet business collaboration, Inter-enterprise interoperation

\section{WHAT IS EM2I?}

In the preparation of this symposium, the term "Electronic Marketplace Integration and Interoperability" was coined as a shorthand way in EM2I to refer to some concerns about supporting the technical integration of multiple business systems so that the expected integration results could further enable a wider scope of both technical and business interoperability across involved business systems. The meaning of the individual words in the term needs clarification and special treatment. What is electronic marketplace? What is integration? What is interoperability?

\subsection{Confusion between Electronic Marketplace and Electronic Market}

Current use of the terms between "electronic marketplace" (EMp) and "electronic market" (EM) is rather confused. For example, in [34], "electronic markets" had a set of e-commerce business models such as "e-shop", "e-procurement", "e-mall", "eauction", "trust service", "info brokerage", "value chain service provider", "virtual community", "collaboration platform", "third-party marketplace" and "value chain integrator". The unclearness here is whether these business models themselves are EM or the systems implementing these models are EM. In [24], the definition of EM, which involves "both human and automated traders", seems that an EM is a technical system. In [31], "an electronic marketplace (or electronic market system) is an interorganizational information system that allows the participating buyers and sellers to exchange information about prices and product offerings ... E-markets provide an electronic, or online, method to facilitate transactions between buyers and sellers".

Please use the following format when citing this chapter:

Guo, J., 2007, in IFIP International Federation for Information Processing, Volume 255, Research and Practical Issues of Enterprise Information Systems II Volume 2, eds. L. Xu, Tjoa A., Chaudhry S. (Boston: Springer), pp. 831-840. 
Two concepts here are interweaving in meaning. A latest study of EMp [39] seems also no distinction between what is an EM and what is an EMp. To the extent we are supposedly trying to support exchanges between the systems of buyers and sellers, we are obliged to answer the question: is EMp responsible for the exchanges or is EM for that?

\subsection{Electronic Marketplace as Infrastructure of Electronic Market}

EMp cannot be defined in a mingled way jammed with market behaviors and construction techniques. It should be separated into clear layers to capture its own nature. An electronic market (EM) inherits the notion of traditional "market" encompassing the behaviors of the exchange of goods and services. In traditional perfect market, the business information necessary for transaction is assumably conveyed by price, and price mechanism is the most important instrument for coordinating and allocating business information [20]. Here price information transferring itself is implicitly implemented through the pervasive mailing systems, face-to-face contacts or any means that can quickly spread price. However, in EM, this is explicitly implemented by a certain technical system (say information exchanging system) underlying the EM. If the use of transferred price information as price mechanism is a kind of EM behaviors, then the information exchanging system that supports these behaviors should belong to another system, i.e. EMp.

Pricing behaviors in market as a whole are invisible and formed by many anonymous and/or named market participants. Studying pricing behaviors (or more broadly market behaviors) is attributed to EM and falls in economic category. In contrast, an electronic marketplace (EMp), originated from traditional "marketplace" as a physical gathering place (e.g. a bazaar or an exhibition center), is a visible technical system on which pricing behaviors happen. It focuses on business information exchange and is in technological category. In this sense, an EM is a superstructure of an EMp, while an EMp is an infrastructure of an EM.

\subsection{Bounded Electronic Market}

EM has an important unique characteristic: it has a clear market boundary constrained by its underlying EMp due to the fact that the freedom of the information exchange is bounded by the make of EMp. Differently, the boundary of a traditional "market" is not clear. This is because, in traditional market, price information transferring is achieved through regular mail systems, face-to-face interactions, etc. This transferring is pervasive and has no system boundary, thus the market extends as price information goes around. This perspective provides a distinction between EM/EMp and traditional market, which can be clearly illustrated in Fig. 1.

The comparison between traditional market and EM/EMp releases an interesting finding that an EMp is an information exchange system, which exchanges business information on behalf of its superstructure (i.e. EM) where people exchange goods and services by using the exchanged information. 


\begin{tabular}{|c|c|c|}
\hline Electronic Market & Superstructure & Traditional Market \\
\cline { 1 - 1 } Electronic Marketplace & Infrastructure & Mail systems, face-face contacts \\
\cline { 3 - 3 } & &
\end{tabular}

Figure 1. Comparison between Electronic Market(place) and Traditional Market

\subsection{Role of Integration}

While an EMp is the infrastructure of an EM, what is "integration" and what is its role in EMp? Early in last decade when Internet just began, Anderson [1, 2] used integration to understand the collaboration relationship between small and large firms and their collaborative linkages that needed to be developed. He thus proposed the term "collaborative integration" $[1,2]$ and defined it to be "instrumental in the restructuring of industries and the local economies" in which "a firm that can successfully incorporate globalization, specialization and collaboration in its corporate strategy will be in a strong position to dominate markets in today's economic climate". Strategically, the term is often used to understand the formation mechanism of a larger regional or global market, for example, the network-linked "Greater Vancouver regional market" [25]. Recently, the term was further used to describe the approaches to EMp construction, for example, "integration hub" through network-level optimization [30].

"Collaboration integration" implies that integration is collaborative. It describes the relationship aggregation of different business systems that form EMp where businesses interoperate with each other. The "integration" and "interoperability" combining together has three levels of meanings: technical integration for technical interoperability, technical integration for business interoperability and business integration for business interoperability. Technically, "integration" is a collaborative process for seamless convergence of technical structures, concepts, services and applications between disparate business systems. Commercially, "integration" means superstructure change of organization and strategy by restructuring and transforming (e.g. vertical integration and strategic alliances) towards either an electronic hierarchy or an EM [19]. The term "interoperability" implies "integration" results for technical capability of working together between business systems and business capability of efficiency increase and cost reduction of organizations. Clearly, integration determines interoperability and interoperability asks for integration.

\section{EM2I AS A RESEARCH AREA}

Should EM2I be a research area? Richard Whitley, a British sociologist, defined that "a research area can be said to exist when scientists concur on the nature of the uncertainty common to a set of problem situations" [40].

Applying this criterion to EM2I, we may ask what are the problem situations addressed by a group of researchers in business systems and electronic commerce? Are they important and difficult problems that are commonly uncertain to these 
researchers? If EM2I positively answer these two questions, it constitutes a research area defined by Whitley.

Taking EM2I apart, the individual characters in the term, electronic marketplace "EM" aspect itself has already attracted many researchers discussing its constructing approaches, for example, "portal" [33], "hub" [32], "exchanges" [22], broker [29], "mediator" [18] and "facilitator" [17] in electronic commerce. Issues of "uncertainty" [3] and "complexities" [16] during the EMp construction drive even more researchers to theories and approaches [37]. These research activities signify that EM2I is worth becoming a research area.

Given the above activities occurred in constructing an EMp, the EM2I will inevitably become a multidisciplinary research, asking for the involvement of both IT technical experts and business specialists from the management aspects.

\subsection{Target Area of EM2I: Electronic Marketplace}

While "marketplace" is a very old concept, the term "electronic marketplace" only appeared and frequently used from 1990s (e.g. [5]). Tracing back to the history, EMp study was originated from the discussion of "wired city" [4], where multiple cities were digitally linked and examples such that housewives could shop through home terminals. The "wired city" concept signified two directions of EMp studies.

"Studies concerned with the regulatory climate of wired city services generally explore a number of options including government ownership of the system ..., regulated monopoly ..., licensed competition ..., and the unregulated or 'free' marketplace ..." [26].

These studies have gradually become the current research aspect of EM, which is the superstructure of EMp.

"Technologically oriented studies focus on the physical aspects of the system.

They are concerned with evaluating various communications media, terminals and system configurations along a cost/benefit axis. They concentrate on the technological problems in providing the services of the wired city [26].

This aspect research, in fact, is the research area of EMp, which provides the infrastructure of its above EM with its main task of business information exchange.

Business information exchange implies many concepts - wire, network, switch, relay, brokerage, mediation, etc. Contemporary researches often used the terms like portal [33], hub [32], exchanges [22], broker [29], mediator [18] and facilitator [17] to describe EMp construction. In all these term usages, there is a common intention that the constructed systems must support a common place or network that could correctly relay or switch the passing information without changing its underlying meaning. To generalize, an EMp can be described as a common business information space (CBIS), which is an information exchange and shared space that allows multiple business systems to work together for exchanging their business information. With the help of this space, business information of different business systems could be exchanged, recorded, processed, summarized and reported. The CBIS is a term borrowed from the general term of common information space (CIS) $[7,8,10,14,28]$ in $\mathrm{CSCW}$ area, which mostly concerns about the essential problem of "how to 
integrate activities that are taking place on different ontological foundations" [27] in different "semantic communities" [27].

\subsection{Characteristics of Electronic Marketplace}

A modern EMp has four characteristics: distribution, autonomy, interdependence and emergence. Distribution refers to that the participated entities (i.e. business systems) of an EMp are Web-distributed. It implies an interconnectivity requirement for information exchange between these systems. Individual business systems are autonomous. "Autonomy denotes the self-determination of components and means that an autonomous entity is governed by its own local laws and consequently does not usually adhere to common concepts or agreements" [15]. Autonomy leads to heterogeneity between entities. Interdependence denotes the mutual links between business systems as required for trading and the mutual influences on their behaviors [15]. The existence of mutual dependence among business systems means that the operations on one business system may influence the operations of the others. In other word, conflicts may happen because of autonomy. Thus, cooperation means operating together towards common concepts by reaching agreements [15]. While autonomy on distribution generates spatial conflicts among business systems, emergence (described in emergence theory $[11,35])$ refers to the different changes of autonomous requirements between business systems that create temporal conflicts, which again require a cooperation mechanism to resolve the conflicts.

Considering these characteristics, the target area of EM2I should be EMp. This should include (1) How to build a reliable business common information space (BCIS), where business systems connectivity mechanism can be presented to collaboratively integrate various participants' business systems. (2) How to build a flexible collaboration mechanism, where discrepancies between various participants can be resolved and a shared understanding with regard to common business vocabularies, documents and processes can be created, processed and exchanged in an integration framework. Besides these, since the "joining" and "leaving" EMp of business systems is determined by the higher level EM participants, EM2I must additionally support the requirement analysis of EMp customers. More specifically, EM2I must support its own EMp modeling analysis for providing better EMp services. This is because EMp itself is profit entity. In this sense, EM2I must further include (3) how to understand the functional requirements of participated business systems, their motivations in terms of business interoperability, their expectations from EMp, and their retroactions on EMp; and (4) how to incorporate these functional requirements by querying which functions are more welcome (e.g. functionalities described in Bakos [6] or in Wang and Archer [37]).

\section{CORE ISSUES FOR EM2I}

Whereas EMp addressing both business requirements and technical problems of business system connectivity and collaboration, it needs to address the following specific requirements: 
- Deconstructing electronic market tasks

- Reconstructing business common information space

- Adapting to the changes of interoperability requirements and e-commerce technologies.

In the author's opinion, meeting these requirements constitute the core issues of the EM2I area.

\subsection{Supporting Deconstruction Work}

EM sitting on EMp has different business tasks. First, tasks belong to the different EM participants: sellers, buyers, governors or others? Second, tasks have goals: which products, what costs, which sellers or buyers, and what level of quality? Third, by assigning goals to the tasks, these tasks can be classified based on functions: purchase, selling, payment or servicing? Fourth, the tasks are performed through a set of activities: how should these activities be linked together for interaction: where and when? Employing the term "deconstruction" [21], the numerous tasks as a requirement ensemble need to be analyzed, differentiated and meshed. In the words of an early translator David Allison of Derrida's work [12], deconstruction "signifies a project of critical thought whose task is to locate and 'take apart' those concepts which serve as the axioms or rules for a period of thought, those concepts which command the unfolding of an entire epoch ...".

An EM is a complex ensemble due to, e.g., the multiplicity of their participants and the uncertainty of their behaviors. In this EM, business requirements cannot be effectively captured and transformed into the EMp construction requirements.

The commonly accepted view of what constitutes an EMp still heavily relies on the traditional bureaucratic brokerage model [19]: people of different business systems perform a number of EM tasks through a broker made according to a set of wellspecified procedures targeted at effectiveness and efficiency. In this model, many assumptions are made on a rational base for action and common behaviors for EM participants. The traditional formal EMp was organized in the hub-spoke form, which presumes a one-way relationship such that all EM participants will follow a set of predefined rules, for example, ontologies. Despite many studies, the early EMp, e.g. EDI on VAN [36] or Smart Catalog [17], developed for automating trade were built by designers who implicitly assumed much of the traditional brokerage model.

Such EMps have now been found insufficient to address new requirements for semantic information exchange [13]. Researchers are beginning to appreciate the complexity of heterogeneous business information systems and the collaboration of exchanging contextual knowledge between them [37, 38]. More recent studies have emphasized the semantic nature of business information and its complexity in exchange between heterogeneous business information systems [13, 23].

So what does it implies for EMp design? Building EMp seems as simply as being concerned with hub for spoke, but neglecting the deconstruction work needed to make "hub" possible for mediating the contextual semantics around spoke. EMp should aim at supporting the tasks of semantic connections of autonomous business information systems as opposed to the simple schematic linkage by a set of single mandatory rules. 


\subsection{Common Business Information Space}

How to support a common business information space (CBIS) is one of the core problems of EM2I. This issue predates e-commerce technology and is fundamental to EMp, although the problems are aggravated by the increased scope and intensity of EMp relations facilitated by e-commerce technology. As characterized with special properties described previously, EMp may work in a distributed, autonomous, emergent yet interdependent way. Because of this, EMp as a workplace must support buyers and sellers matching, transaction facilities, and legal and security infrastructures. In addition to that, it requires the collective and semantic interaction between participated business information systems. This gives rise to a series of problems, quite apart from the technical problems of standardization, ontology design and so on so forth. We give a brief account of some of the problems below.

First, people prefer a semantically connected environment for business interoperability. Accordingly, EMp functions supporting business interoperability are semantically inherited. They are not only the requirements of EM participants but also the results of semantic reconstruction. In this reconstruction, EMp has to become a common place where functions could semantically interoperable as described in Berners-Lee et al's system [9]:

"... At the doctor's office, Lucy instructed her Semantic Web agent through her handheld Web browser. The agent promptly retrieved information about Mom's prescribed treatment from the doctor's agent, looked up several lists of providers, and checked for the ones in-plan for Mom's insurance within a 20-mile radius of her home and with a rating of excellent or very good on trusted rating services. It then began trying to find a match between available appointment times... and Pete's and Lucy's busy schedules ..." [9].

Thus, EMp functions involve semantically understandings that follow the instructions of human being.

Second, human instructions are always generated in an individual context. A context is an autonomous perspective of something that is different from another. In face-to-face communication systems, natural languages are used following a disambiguation model to pass instructions or messages. However, an EMp is distributed, where people are mediated by computer systems. Thus, people's semantic messages must firstly be interpretable by computers and secondly computers as agents must accurately convey people's semantic messages to other people despite of heterogeneous contexts. This requires context transformation mechanism in designing EMp.

Yet, however, the third problem is that human messages passing through computer agents are not static. They are emergent as people's new idea or new actions come. This implies that the used vocabularies, documents and processes underlying the heterogeneous contexts between people could not be statically transformed. A collaboration mechanism must then be developed to support the negotiation of the use of vocabularies, documents and processes. With collaboration, conflicts between EMp participants could be resolved and common vocabularies, business documents and processes across domains and heterogeneous business systems could be gradually created. 


\subsection{Design of Electronic Marketplace}

EMp is characterized by distribution, autonomy, emergence and interdependence, and holds the responsibility of business interoperability. The changes in distribution scope, intensity of autonomy, speed of emergence and closeness of interdependence reshape the design of $\mathrm{EMp}$, which may further change the business interoperability requirements for the combination of EMp functions. First, the distribution scope determines the size of an EMp, for example, within a regional, a national or an international EMp. As interoperability requirements force the scope to be larger, the connectivity constraints limit the expansion in the levels of strategy, organization, technology and legal boundaries. For example, an order signed between two firms in Alibaba (alibaba.com) using Alipay signatures can be protected under China's laws but may not be protected outside of China. Second, the extent of autonomy and the semantic connectivity determines the interoperability of EMp. For example, in Alibaba all participants' information systems have higher autonomy for products uploading and displaying through Alibaba product catalogs, and business negotiation through Alibaba's TradeManagers, but they have lower business interoperability in automatic business communication such as automatic product search, product inquiry and offer, and price negotiation. On the contrary, e-payment systems like TradeCard.com and Bolero.net have relatively low autonomy in comparison but high business interoperability with regard to business automation. Third, the speed of emergence in business interoperability requirements also asks for flexibility and semantic adaptation to the changing contexts of business. All these are closely interdependent and demand us to view the changing EMp as a dynamic CBIS.

Thus, the author believes that the designers of EMp must be able to distinguish analytically the multitude of forms of business interoperability requirements that play a part in shaping an EMp in any real world setting, for example:

- The interoperability scope of "regional", "national", or "international";

- The level of semantic requirement for integration;

- The autonomy requirement for participated business systems;

- The adaptability to the changes of EMp functions and their retroactions; and so on so forth.

The theoretical framework that would help designers to deal with these issues, however, is not imminent. EM21 area is new and in short of detailed studies on its effects on the nature of work process in EMp. Thus, we need to have more designs and implementations of trial and commercial EMp, as well as to perform more detailed empirical studies to existing EMp to observe their effects.

\section{CONCLUSIONS}

EM2I is a new research area where electronic marketplaces will be built as the infrastructure of electronic markets. In the building process, business interoperability requirements force the adoption of integration methodology such that heterogeneous business information systems are integrated into a common business information 
space where electronic marketplace participants can work together online in a semantic way.

\section{REFERENCES}

1. M. Anderson, Collaborative integration in the Canadian pharmaceutical industry, Environment and Planning. Volume 25, Number 12, pp. 1815-1838, (1993).

2. M. Anderson, The Role of Collaborative Integration in Industrial Organization: Observations from Canadian Aerospace Industry, Economic Geography. Volume 71, Number 1, pp.55-78, (1995).

3. J. Arnoldi, Frames and screens: the reduction of uncertainty in electronic derivatives trading, Economy and Society. Volume 35, Number 3, pp.381-399, (2006).

4. J. Auwaerter, Data Transmission, Communications of the ACM. Volume 7, pp.44-58, (1970).

5. Y. Bakos, A Strategic Analysis of Electronic Marketplaces, MIS Quarterly. Volume 15, Number 3, pp.295-310, (1991).

6. Y. Bakos, The Emerging Role of Electronic Marketplaces on the Internet, Communications of the ACM. Volume 41, Number 8, pp.35-42, (1998).

7. L. Bannon and S. Bødker, Constructing Common Information Spaces, in Proc. Of ECSCW'97 (Lancaster: UK, Sept 1997).

8. L. Bannon, Understanding Common Information Spaces in CSCW, in: Workshop on Cooperative Organization of Common Information Spaces (Technical University of Denmark, 2000). http://dmm.cti.dtu.dk/position/bannon.pdf

9. T.B. Lee, J. Hendler, and O. Lassila, The Semantic Web, Scientific American. Number $5,(2001)$.

10. C. Bossen, The Parameters of Common Information Spaces: the Heterogeneity of Cooperative Work at a Hospital Ward, in ACM CSCW'02 (USA, 2002), pp.176-185.

11. J. Damsgaad and D. Truex, Binary Trading Relations and the Limits of EDI Standards: The Procrustean Bed of Standards, Eur J Inf Syst. Volume 9, Number 3, pp.173-188, (2000).

12. J. Derrida, Speech and Phenomena and Other Essays on Husserl's Theory of Signs, translator B.A. David (Northwestern U.P., Evanston, 1973).

13. J. Guo and C. Sun, Context Representation of Product Data, ACM SIGEcom Exchanges. Volume 4, Number 1, pp.20-28, (2003).

14. J. Guo and C. Sun, Global Electronic Markets and Global Traditional Markets, Electronic Markets. Volume 14, Number 1, pp.4-12, (2004).

15. J. Hall and V. Tschammer, Autonomy and Cooperation in distributed CIM Systems, in: Proc. of 3rd workshop on ACM SIGOPS European workshop (Cambridge: UK, 1988).

16. C. Hine, Internet Research and the Sociology of Cyber-Social-Scientific Knowledge, The Information Society. Volume 21, pp.239-248, (2005).

17. Keller, Smart catalogs and virtual catalogs, in Readings in electronic commerce (Addison-Wesley Longman: Boston, 1997).

18. M. Lincke and B. Schmid, Mediating electronic product catalogs, Communications of the ACM. Volume 41, Number 7, pp.86-88, (1998).

19. T.W. Malone, J. Yates, and R.I. Benjamin, Electronic Markets and Electronic Hierarchies, Communications of the ACM. Volume 30, Number 6, pp.484-497, (1987). 
20. P. Milgram and J. Roberts, Economics, Organization, and Management (Prentice-Hall: New York, 1992).

21. J. Moormann, Deconstruction of the Value Chain in the Banking Industry, in: International Conference Taganrog/Russia (September 2003).

22. C. Nøkkentved, Collaborative Processes in e-Supply Networks, ECoE Research Report (PriceWaterhouseCoopers, August 2000).

23. T. Noia, E. Sciascio, F. Donini, and M. Mongiello, Semantic matchmaking in a P-2-P electronic marketplace, in SAC 2003 pp.582-586 (Melboure, U5A, 2003).

24. B. Rachlevsky, I. Ben-Shaul, N. Chan, A. Lo, and T. Poggio, GEM: A Global Electronic Market System, Information Systems. Volume 24, Number 6, pp.495-518, (1999).

25. K. Rees, Interregional Collaboration and Innovation in Vancouver's Emerging HighTech Clusters, Tijdschrift voor Economische en Sociale Geografie. Volume 96, Number 3, pp.298-312, (2005).

26. R. Rittenhouse, The Market for Wired City Service, ACM SIGCAS Computer and Society. Volume 10, Number 2, pp.2-13, (1979).

27. M. Robinson and L. Bannon, Questioning Representations, in Proc. of ECSCW, eds. L. Bannon, M. Robinson, and K. Schmidt, pp.219-233 (Kluwer: Dordrecht, 1991).

28. K. Schmidt and L. Bannon, Taking CSCW Seriously: Supporting articulation work, Computer Supported Cooperative Work. Volume 1, Number 1-2, pp.7-40, (1992).

29. A. Segev and C. Beam, Brokering strategies in electronic commerce markets, in $E$ Commerce 99 (ACM Press: 1999), pp.167-176.

30. M. Sloan, Performance Benefits through Integration Hub, Communication of the ACM. Volume 48, Number 4, pp.95-100, (2005).

31. T. Strader and M. Shaw, Characteristics of Electronic Markets, Decision Support Systems. Volume 21, pp.185-198, (1997).

32. K. Takemoto, K. Senda, A. Oshima, and H. Shibata, Hitachi Review (2002). www.hitachi.com/rev/archive/2002/2005999 12608.html (Accessed August 17, 2005).

33. S. Thompson, M. Cioffi, H. Gharib, N. Giles, Y. Li, and T. Nguyen, From Trips to Telcos - Next Generation Service Portals, BT Technology Journal. Volume 24, Number 1, pp.27-39, (2006).

34. P. Timmers, Business Models for Electronic Markets, Electronic Markets. Volume 8, Number 2, pp.3-8, (1998).

35. D. Truex, R. Baskerville, and H. Klein, Growing Systems in Emergent Organizations, Communication of the ACM. Volume 42, Number 8, pp.117-123, (1999).

36. M. Unitt and I. Jones, EDI - The Grand Daddy of Electronic Commerce, $B T$ Technology Journal. Volume 17, Number 3, pp.17-23, (1999).

37. S. Wang and N. Archer, Strategic Choice of Electronic Marketplace Functionalities: A Buyer-Supplier Relationship Perspective, Journal of Computer-Mediated Communication. Volume 10, Number 1, pp.11, (2004).

38. S. Wang and N. Archer, Supporting Collaboration in Business-to-Business Electronic Marketplaces, Information Systems and e-Business Management. Volume 2, pp.269286, (2004).

39. S. Wang and N. Archer, Electronic Marketplace Definition and Classification: Literature Review and Clarifications, Enterprise Information Systems. Volume 1, Number 1, pp.89-112, (2007).

40. R. Whitley, Cognitive and Social Institutionalization of Scientific Specialties and Research Areas, in Social Processes of Scientific Development, eds. Whitley (Routledge and Kegan Paul: London), pp.69-95, (1974). 